\title{
Non-isothermal pyrolysis of cashew shell cake-bituminous coal blends
}

\author{
Yoon Hwa Park, Ho Young Park ${ }^{\dagger}$, Hyun Hee Kim, Sang Bin Park \\ KEPRI, 105 Munji-Ro, Yuseong-Gu, Daejeon 34056, Republic of Korea
}

\begin{abstract}
This paper describes the non-isothermal pyrolysis of cashew shell cake (CSC) - bituminous coal blends. The blends exhibit two distinct stages in the thermogravimetric curves, which the first stage stems from CSC and the second one from the superposition of CSC and coal pyrolysis. The pyrolysis behavior of the blend was linearly proportional to the blending ratios. The overall behavior of the blends was evaluated in terms of the maximum rate of weight loss, characteristic temperatures, char yields, and the calculated and experimental thermogravimetric curves. The activation energies ranged up to $49 \mathrm{~kJ} / \mathrm{mol}$ for the blends were obtained and used to evaluate the interaction in the blends. The present thermogravimetric study shows that there is no significant interaction between CSC and coal in the blends, and it was supported by the characteristic values which are linearly proportional to the weight percentages of cashew cake-shell in the blends. The no-interaction might be due to the fact that the main reaction zones are distinctively different for two constituents, so the additive rule is acceptable for describing pyrolysis behavior of the present blends.
\end{abstract}

Keywords: Cashew shell cake, Coal, Kinetics, Non-isothermal, Pyrolysis, TGA

\section{Introduction}

There has been a great interest in the use of lignocellulosic biomass for the power generation. The utilization of lignocellulosic biomass in the power plant does not produce the net $\mathrm{CO}_{2}$ emission since the same amount of $\mathrm{CO}_{2}$ was extracted from the atmosphere during the plant growth. Generally, lignocellulosic biomass can be categorized into three main groups, namely agricultural wastes, energy crops, and forestry residues from forest logging sites [1, 2]. Currently, lignocellulosic biomass is generated significantly as a by-product on a global scale, with a projected production rate of 680 million tons annually by 2030 in the United States alone [3]. Various types of lignocellulosic biomass have used for power generation. Woody lignocellulosic biomass largely utilized in the coal-fired power plant includes wood pellet (WP) and chips, saw dust, tree trimmings and municipal tree, while agricultural wastes such as straw, nut shell, switch glass and rice husk have been also used for power generation. It is considered sensible to utilize lignocellulosic biomass for co-firing in the coal-fired power plant. Although the co-firing lignocellulosic biomass with pulverized coal in a boiler is the simple and convenient way for the utilization of lignocellulosic biomass, there have been many technical issues. The major technical areas of concern are associated with the higher fuel volume and moisture content, lower ash melting point compared to coal, slagging and fouling tendency, chlorine level, and degradation of selective catalytic reduction (SCR) catalysts, etc. $[4,5]$.

WP has been widely used in pulverized coal-fired boilers in Korea, and $4 \%$ of lignocellulosic biomass is usually mixed with $96 \%$ of pulverized coal on the basis of thermal input. WP is the most popular lignocellulosic biomass in Korea and the amount used in a $500 \mathrm{MW}$ coal-fired boiler reaches around 34,000 ton/y. The equivalent power generation by WP equals to $63,000 \mathrm{MWh} / \mathrm{y}$ and its effect on the reduction of $\mathrm{CO}_{2}$ is estimated to be 50,000 $\mathrm{CO}_{2}$ ton/y. Although WP is the most popular lignocellulosic biomass in Korea, majority of WP has been imported from other countries at relatively expensive price. The production of domestic WP was reported to be around 820,000 ton/y in 2015. Wood chip (WC) is also the main lignocellulosic biomass used in Korea. About 373,000 ton/y has been produced domestically and half of them has been used in the $30 \mathrm{MW}$ WC fluidized bed power plant. Since the lignocellulosic biomass like WP and WC is very limited resource
This is an Open Access article distributed under the terms of the Creative Commons Attribution Non-Commercial License (http://creativecommons.org/licenses/by-nc/3.0/) which permits unrestricted non-commercial use, distribution, and reproduction in any medium, provided the original work is properly cited.
Received January 23, 2017 Accepted September 5, 2017

${ }^{\dagger}$ Corresponding author

Email: hypark22@kepco.co.kr

Tel: +82-42-865-5641 Fax: +82-42-865-5679

Copyright (C) 2018 Korean Society of Environmental Engineers 
in Korea, there have been some trials to diversify the resource of lignocellulosic biomass, and these include coffee residue, imported empty fruit bunch, domestic saw dust, cashew shell cake (CSC), and solidified sludge, etc. Among these lignocellulosic biomass, the present study is focusing on CSC.

Cashew shell (CS) is known to be by-product of cashew industry. Cashew nut is covered by a shell of about $2-3 \mathrm{~mm}$ thickness. Cashew nut shell liquid (CNSL) is extracted from the CS, and the residue after the extraction of CLSL from CS is CSC [6, 7]. There have been several studies on the kinetics of CS with thermogravimetric analysis (TGA) and reported that the CS is different with ordinary woody lignocellulosic biomass of enriched hydrocarbons [8-10]. Concerning CSC thermal decomposition, only one study has been found in the literature [9], which is comparing the thermal decomposition kinetics of CS and CSC. The study claimed that CS is a different bio-material than CSC. In the literature, the study on the pyrolysis of CSC-coal blends has not been found elsewhere, so the present study is focusing on the TGA pyrolysis behavior of CSC-coal blend. In the present study, the products distribution and rate of biomass pyrolysis has not been investigated, and only the overall weight loss has been used to describe the pyrolysis behavior of the present samples. Generally, the composition of pyrolytic volatiles of lignocellulosic biomass has been described by means of a relevant number of species: $\mathrm{H}_{2} \mathrm{O}$, tar, $\mathrm{CO}_{2}, \mathrm{CO}, \mathrm{H}_{2}, \mathrm{CH}_{4}$ and other light hydrocarbons [11].

In the present study, the temperature programmed, non-isothermal thermogravimetric analysis was adopted to study the pyrolysis behavior of the CSC-coal blend as well as the interaction between CSC and coal in the blend. CSC was blended with bituminous coal at the ratios of 20:80, 40:60, 60:40, 80:20 for CSC and coal on the basis of weight percentage. The overall pyrolysis characteristics for CSC-coal blends are evaluated in terms of the maximum rate of weight loss, characteristic temperatures, char yields and the calculated thermogravimetric (TG) \& differential thermogravimateric (DTG) curves. The kinetic data for the blends were obtained with the multi-stage Coats and Redfern method and used to check the interaction between CSC and coal in the blends.

\section{Experimental}

\subsection{Materials}

Austrailian bituminous coal (Glencore coal) was sampled from a $500 \mathrm{MW}$ power plant, and the sampled coal was ground and sieved to fine particles of less than $75 \mu \mathrm{m}$ (200 mesh). The sieved coal was used to make the binary CSC-coal blends for TGA tests. The lignocellulosic biomass types used in the present study was CSC after oil extraction, and Fig. 1 shows CSC sample before the grinding. The sample was ground and prepared with their sizes to be less than $75 \mu \mathrm{m}$. The blends tested were prepared with four different CSC-coal blending ratios of 20:80, 40:60, 60:40, 80:20 on the basis of weight percentage. Ultimate and proximate analysis, lignocellulose components for coal and CSC were obtained by standard procedures and their values are presented in Table 1.

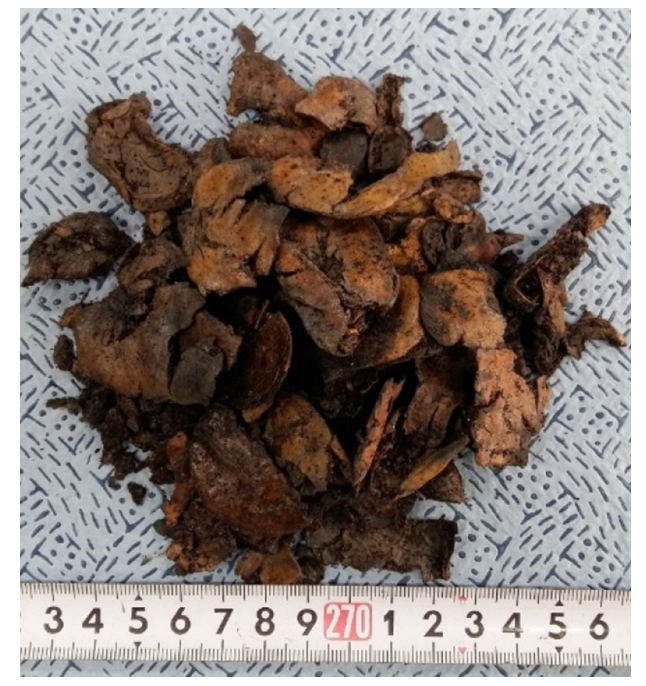

Fig. 1. Photo of CSC used in the study.

Table 1. Properties of Biomass and Coal

\begin{tabular}{lcc}
\hline \multicolumn{1}{c}{ Material } & CSC & Coal \\
\hline Proximate analysis (wt.\%) & & \\
\hline moisture & 6.64 & 9.81 \\
ash & 3.08 & 8.53 \\
volatile & 71.7 & 34.52 \\
fixed carbon & 18.58 & 47.13 \\
\hline Ultimate analysis (wt.\%) & & \\
\hline C & 54.82 & 78.58 \\
H & 7.17 & 5.25 \\
O & 36.86 & 13.74 \\
N & 1.14 & 2.01 \\
S & 0.01 & 0.42 \\
\hline Heating value (kcal/kg) & 4263 & 6761 \\
\hline Lignocellulosic composition (wt.\%) & & \\
\hline acetone solution & 8.40 & \\
hot-water extract & 25.61 & \\
ligin & 25.11 & \\
Holocellulose (hemicellulose+cellulose) & 38.51 & \\
\hline
\end{tabular}

\subsection{Thermogravimetric Experiment}

The pyrolysis characteristics of CSC-coal blends were studied by using TGA (Setsys Evolution, Setaram) in the temperature programmed heating mode. Each sample was heated at $10^{\circ} \mathrm{C} / \mathrm{min}$ from room temperature to $1,000^{\circ} \mathrm{C}$. To minimize the experimental error, the diffusion effect on the sample was checked with several sample weight and reaction flow rates in all TGA runs. Approximately $10 \mathrm{mg}$ of sample and flow of $100 \mathrm{~mL} / \mathrm{min}$ for $\mathrm{N}_{2}$ were used. Those sample weight and gas flow were obtained from the preliminary tests to ensure the chemically controlled condition with the several sample weights and gas flows. 


\subsection{Kinetic Analysis}

The Coats and Redfern integral method is widely used in analyzing the non-isothermal kinetic parameters for the pyrolysis of solid fuel, and adopted in the present study. The Coats and Redfern equation is given as:

$$
\ln \left[\frac{-\ln (1-x)}{T^{2}}\right]=\ln \frac{A R}{\beta E}-\frac{E}{R T}
$$

where $x$ is the conversion fraction of tested sample, $t$ is the time in minutes. The plot of $\ln \left[-\ln (1-\mathrm{x}) / T^{2}\right]$ versus $1 / T$ gives a straight line, so the activation energy (E) and frequency factor (A) can be determined from the slope $(-\mathrm{E} / \mathrm{R})$ and intercept of the regression line, respectively.

To describe the thermal behavior of CSC-coal blends, the present study adopted this reaction scheme, namely, the consecutive, multi-stage, Coats and Redfern equation, and the kinetic parameters for each stage were obtained for the present samples. The experimental conversion curves of the pyrolysis for the samples were again fitted with the obtained kinetic parameters to ensure the validity of the present kinetic analysis. The fitted conversion data are given as follows:

$$
x=1-\exp \left[-\frac{A R T^{2}}{\beta E} \exp ^{-\frac{E}{R T}}\left(1-\frac{2 R T}{E}\right)\right]
$$

The experimental conversion data were compared with the fitted conversion data of Eq. (2), and the comparisons are given in terms of the standard deviation $\left(\mathrm{R}^{2}\right)$ between the experimental and fitted conversion data.

\section{Results and Discussion}

\subsection{Single Fuels}

The TG and DTG curves of coal and CSC are shown in Fig. 2(a) and (b), respectively. The de-watering stage commonly occurs below $150^{\circ} \mathrm{C}$ for two samples. After the moisture evolution, the initial pyrolysis starts at $354^{\circ} \mathrm{C}$ for coal, $206^{\circ} \mathrm{C}$ for CSC, and the pyrolysis continues until $1,000^{\circ} \mathrm{C}$. The DTG curve of CSC in Fig. 2(b) shows a rapid weight loss due to the thermal decomposition of hemi-

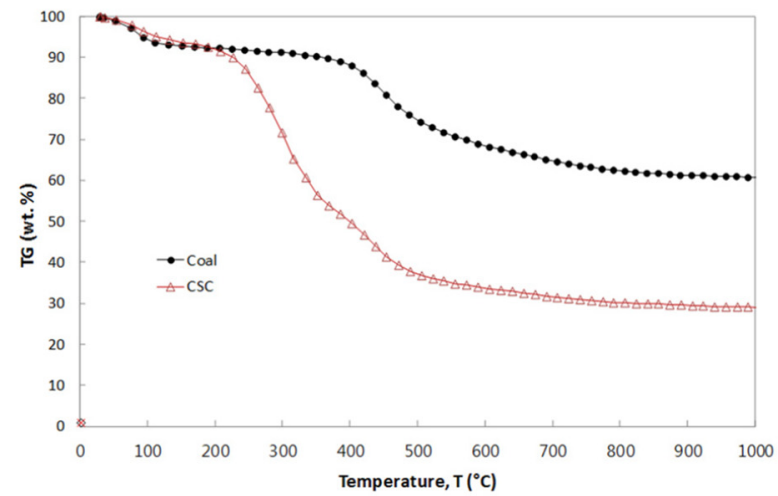

Fig. 2. TG sand DTG curves for coal and CSC. celluloses and cellulose, and then the subsequent weight losses attribute to lignin decomposition. It has been reported that the thermal decomposition for CSC starts around $200^{\circ} \mathrm{C}$ with hemicelluloses in the parent lignocellulosic biomass and reaches the peak around $238^{\circ} \mathrm{C}$, and subsequently cellulose components are decomposed twice at $298^{\circ} \mathrm{C}$ and $418^{\circ} \mathrm{C}$. The decomposition of lignin component in CSC occurs around $100-800^{\circ} \mathrm{C}$ and peaks around $418^{\circ} \mathrm{C}[6]$.

The TG and DTG curves of CSC show the relatively earlier and slower weight loss, and two distinct peaks of 3.8 and 1.7 wt.\%/min occur around $299^{\circ} \mathrm{C}$ and $421^{\circ} \mathrm{C}$, respectively. The second peak in the DTG curve of CSC is very clear and it is similar to that of coal, so it seems to be due to the coal-like volatiles such as higher hydrocarbon. The earlier and quicker pyrolysis of CSC, compared to coal, has been explained with the weaker bond energy of their molecular structure. A value of $380-420 \mathrm{kJmol}^{-1}$ for the bond energy of hemi-cellulose, cellulose and lignin is much lower than $1,000 \mathrm{kJmol}^{-1}$ of $\mathrm{C}-\mathrm{C}$ aromatic bond of polycyclic aromatic hydrocarbons exhibited in coal [12].

In the present TG and DTG curves of themogravimetric analysis, the following characteristic temperatures have been used to characterize the pyrolysis behavior. Initial pyrolysis temperature (IT) is the temperature at which the rate of weight loss exceeded 0.3 wt.\%/min after the moisture evolution, and burnout temperature (BT) is the temperature at which the rate of weight loss decreased to 0.3 wt.\%/min. Peak temperature (PT) is the temperature at which the rate of weight loss was maximum. At PT, the peak height in DTG curve represents the maximum rates of weight loss, $\left[\mathrm{d}\left(\mathrm{W} / \mathrm{W}_{0}\right) / \mathrm{dt}\right]_{\max }$, and it was designated as R (wt.\%/min). In Fig. 2(b), two peak heights of CSC are designated as $\mathrm{R}_{1}$ and $\mathrm{R}_{2}$ (wt.\%/min) corresponding to $\mathrm{PT}_{1}$ and $\mathrm{PT}_{2}$, respectively. Table 2 presents the values for IT, PT, BT, R and the char yields for the present CSC-coal blends. The higher R and lower IT of CSC show that the lignocellulosic biomass pyrolysis is quicker and has more volatiles than coal pyrolysis, and the pyrolysis finish at the temperatures of $553^{\circ} \mathrm{C}$ for CSC and $698^{\circ} \mathrm{C}$ for coal.

$\mathrm{Wu}$ et al. [13] reported that, among lignocellulosic components, cellulose has exhibited the positive effects on the pylolysis behavior of its blends with bituminous coal, while hemicelluloses and lignin exhibited the negative effects. The positive or negative effects with the addition of lingocellulose components in the blends were

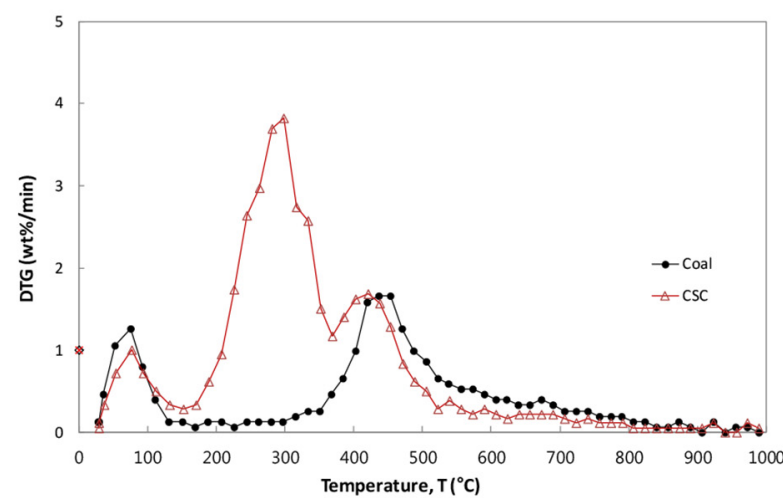


explained with the increases diffusion of volatiles on the cellulose and coal, blocking effect on the volatile evolution of the blends, and the swelling of lignin component with some melting and blocking of the pore. They mentioned that three main components may compete against each other during the pyrolysis, so the synergistic effects in the blends may depends on the competition effects of three model components. Since the positive and negative effects varied with the blending ratio and temperature range, further studies for the lignocellulose components in the present CSC are necessary.

\subsection{Lignocellulosic Biomass-coal Blends}

The TG \& DTG curves of CSC-coal blends, together with those of the parent coal and CSC, are given in Fig. 3(a) to (b), respectively. To investigate the effects of blending ratio on the pyrolysis behavior of the blend, it is convenient to compare the experimental TG and DTG curves of the blends with the calculated ones. The calculated TG and DTG curves were obtained by the weighted sum of TG and DTG curves for each component, and the calculated weight loss of the blends, $W_{\text {cal }}$, is expressed as follows:

$$
W_{c a l}=x_{b} W_{b}+x_{c} W_{c}
$$

where $x_{b}$ and $x_{c}$ are the mass fractions of CSC and coal in the blends, and $W_{b}$, and $W_{c}$ are the weight losses of CSC and coal in the individual TGA test, respectively.

Similarly, the calculated rate of weight loss, $(d W / d t)_{c a l}$, is the weighted summation of the individual rate of weight loss, $(d W / d t)_{b}$ and $(d W / d t)_{C}$ for CSC and coal, respectively, and it is expressed as follows:

$$
\left(\frac{d W}{d t}\right)_{c a l}=x_{b}\left(\frac{d W}{d t}\right)_{b}+x_{c}\left(\frac{d W}{d t}\right)_{c}
$$

In Fig. 3(a) and (b), the experimental TG and DTG curves (marked with symbols) for CSC-coal blends are compared with the calculated ones (marked with lines). It is clearly seen that all the calculated lines are almost overlapped with the experimental data. After the de-watering stages occurred under $150^{\circ} \mathrm{C}$, the first peaks represent the CSC pyrolysis, and the second ones are the summation of the rates of weight loss for both CSC and coal. The shapes of the first peaks in the DTG curves are proportional to the blending ratio, that is, the first peak decreases with increase of the CSC fraction in the blend. The second peaks show almost the same heights for all CSC-coal blends.

The respective deviations between the experimental and calculated TG and DTG data, $\mathrm{RMS}_{\mathrm{TG}}$ and $\mathrm{RMS}_{\mathrm{DTG}}$, have been used to evaluate the extent of interaction in the blend [13]. The smaller value represents the smaller interaction between two components in the blend, and they are calculated as follows:

$$
\begin{gathered}
R M S_{T G}=\sqrt{\frac{\left.\sum_{i=1}^{n}\left[W_{e x p}^{i}-W_{c a l}^{i}\right) / W_{c a l}^{i}\right]^{2}}{n}} \\
R M S_{D T G}=\sqrt{\frac{\sum_{i=1}^{n}\left[\left(\frac{d W}{d t}\right)_{e x p}^{i}-\left(\frac{d W}{d t}\right)_{c a l}^{i}\right]^{2} /\left(\frac{d W}{d t}\right)_{\max }^{2}}{n}}
\end{gathered}
$$

where $W_{\text {exp }}$ and $W_{\text {oal }}$ (See Eq. (3)) are the experimental and calculated weights of the blends, respectively, and $n$ refers to the number of weight data. The term $\left(\frac{d W}{d t}\right)_{\text {exp }}$ is the experimental rate of the weight loss, and $\left(\frac{d W}{d t}\right)_{c a l}$ is the calculated one given by Eq. (4). The term $\left(\frac{d W}{d t}\right)_{\max }$ is the experimental maximum value in the DTG curve.

The $\mathrm{RMS}_{\mathrm{TG}}$ values for CSC-coal blends are all less than $2.3 \%$, which are quite small values when comparing them to $17.4 \%$ by $\mathrm{Lu}$ et al. [14] and $11.09 \%$ by Meng et al. [12]. The values of $\mathrm{RMS}_{\mathrm{DTG}}$ for CSC-coal blends are ranged from $1.9 \%$ to $4.4 \%$, which are reasonable values compared to $6 \%$ given by the independent parallel reaction scheme of Anca-Couce et al. [15]. The present values are quite reasonable to be accepted as no-interaction between two components in the blends.

As seen in Fig. 3(b), DTG curves of CSC-coal blends represent two distinct peaks. The first peaks stem from CSC, and the second peaks are resulted from the superposition of CSC peak and coal peak in the blend. If there is no-interaction between lignocellulosic biomass and coal in the blend, the PT would not be varied with the blending ratio, while the peak heights (R) would be proportional
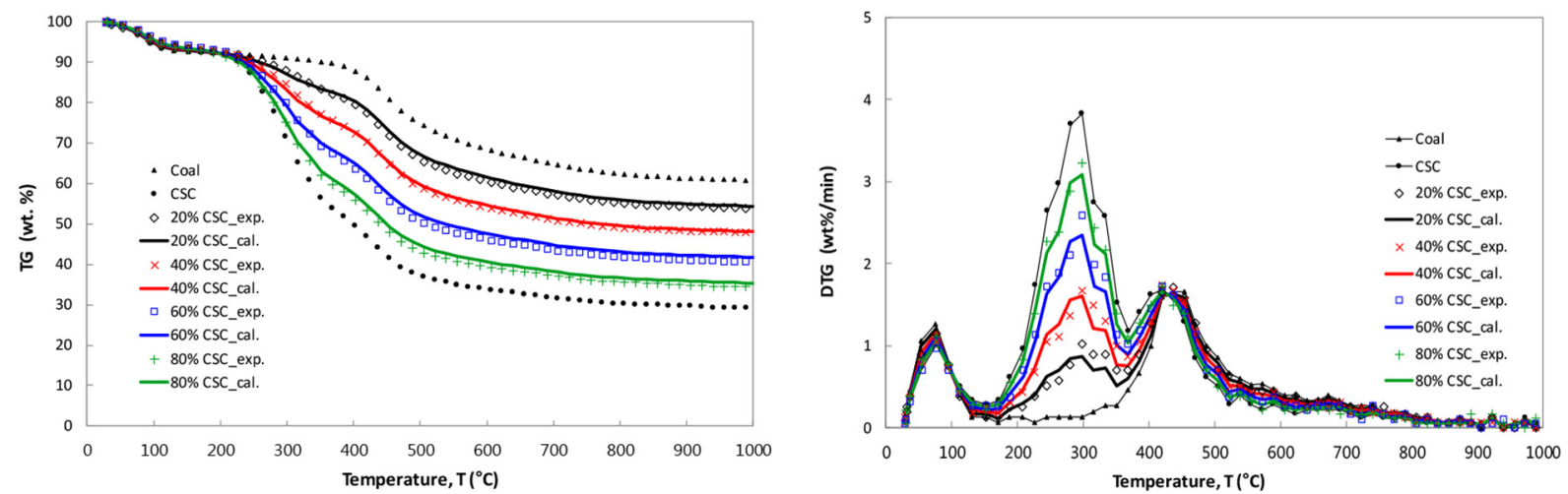

Fig. 3. The experimental and calculated TG and DTG curves for the blends. 
Table 2. Characteristic Parameters for the Present Biomas-coal Blends

\begin{tabular}{|c|c|c|c|c|c|c|c|c|}
\hline \multicolumn{2}{|c|}{ Pyrolysis } & \multirow{2}{*}{$\begin{array}{c}\text { IT }\left({ }^{\circ} \mathbf{C}\right) \\
354\end{array}$} & \multirow{2}{*}{$\begin{array}{c}\mathbf{P T}_{\mathbf{1}}\left({ }^{\circ} \mathbf{C}\right) \\
445\end{array}$} & \multirow{2}{*}{$\begin{array}{c}\mathbf{R}_{\mathbf{1}} \text { (wt.\%/min) } \\
1.66\end{array}$} & \multirow[t]{2}{*}{$\mathrm{PT}_{2}\left({ }^{\circ} \mathrm{C}\right)$} & \multirow[t]{2}{*}{$\mathbf{R}_{2}$ (wt.\%/min) } & \multirow{2}{*}{$\begin{array}{c}\text { BT }\left({ }^{\circ} \mathbf{C}\right) \\
698\end{array}$} & \multirow{2}{*}{$\begin{array}{c}\text { char yield (wt.\%) } \\
60.8\end{array}$} \\
\hline Coal & 100 & & & & & & & \\
\hline \multirow{5}{*}{$\begin{array}{l}\text { wt.\% } \\
\text { of CSC }\end{array}$} & 20 & 214 & 298 & 1.02 & 437 & 1.72 & 633 & 53.9 \\
\hline & 40 & 187 & 298 & 1.68 & 420 & 1.74 & 626 & 47.8 \\
\hline & 60 & 176 & 298 & 2.60 & 420 & 1.73 & 601 & 40.6 \\
\hline & 80 & 172 & 298 & 3.23 & 420 & 1.72 & 561 & 34.2 \\
\hline & 100 & 159 & 299 & 3.82 & 421 & 1.68 & 553 & 29.0 \\
\hline
\end{tabular}
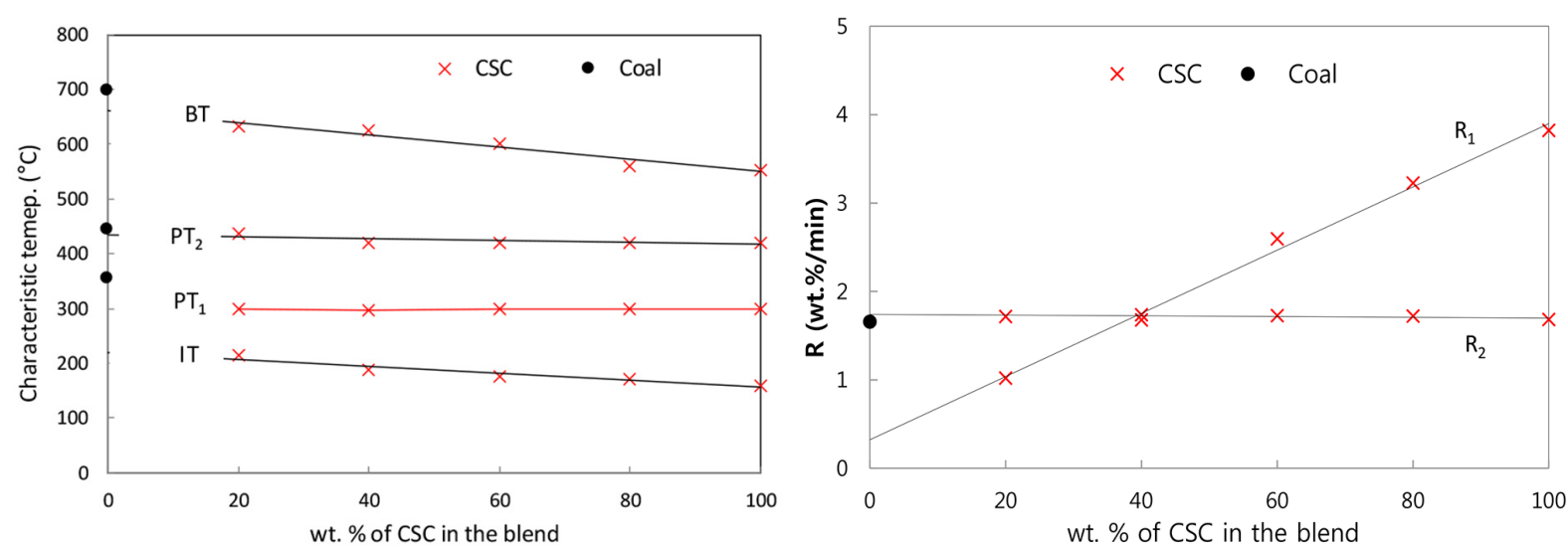

Fig. 4. Characteristic temperatures and peak heights against the blending ratio.

to the blending ratio. Fig. 4(a) and (b) show the variations of characteristic temperatures and peak heights depending on the blending ratio, respectively. The first $\mathrm{PTs}\left(\mathrm{PT}_{1}\right)$ are remained within $\pm 1.0^{\circ} \mathrm{C}$ at $298^{\circ} \mathrm{C}$ for CSC-coal blends. The corresponding peak heights $\left(\mathrm{R}_{1}\right)$ are varied linearly with the blending ratio. The second peak heights $\left(\mathrm{R}_{2}\right)$ are nearly constant for all blending ratios, and the second PTs $\left(\mathrm{PT}_{2}\right)$ are remained in the temperature of $420-437^{\circ} \mathrm{C}$. As given in Table 2 and Fig. 4(a), the IT of the blends decreases gradually with the increase of CSC percentage in the blends. The present CSC has relatively lower BT of $553^{\circ} \mathrm{C}$ (compared to the temperature of $698^{\circ} \mathrm{C}$ for the present coal), so the increase of CSC percentage in the blends leads to decrease of the BT.

The char yields in the pyrolysis of CSC-coal blends have been used to evaluate the interaction in the blend. If there is no interaction between CSC and coal in the blend, the char yields of the blend would be an arithmetic average of the individual char yield in additive manner [8, 10, 13]. The present char yields of coal, CSC and their blends against the blending ratio are plotted in Fig. 5, and the linearity indicates no-interaction between two components in the blend.

The experimental TG and DTG curves are quite well coincided with the calculated ones. The calculated shapes, peak temperatures and heights, and char yields of the blends well describe the experimental ones, which mean the additive rule is quite acceptable for describing the pyrolysis of the present CSC-coal blends. Overall, the present thermogravimetric curves show that there is no significant interaction between CSC and coal in the blends, and it might be due the fact that the main reaction zones are distinctively different for two constituents. The additive rule is acceptable for describing pyrolysis behavior of the present blends.

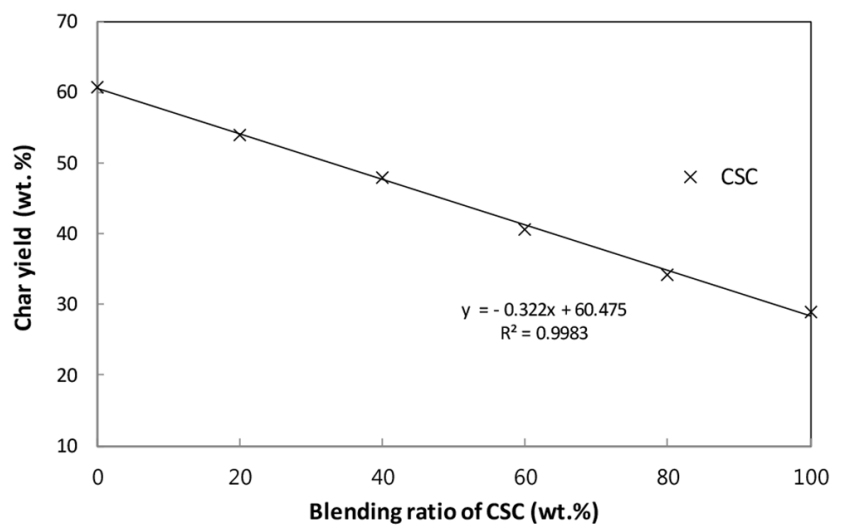

Fig. 5. Char yield against the blending ratio.

\subsection{Kinetic Parameters}

Table 3 shows the activation energies (E) and frequency factors (A) for the present CSC-coal blend pyrolysis, obtained with the multi-stage, Coats and Redfern method. Fig. 6(a) and (c) represent the experimental conversion (x) of the coal and CSC, respectively. In the figures, the lines are the fitted conversion data (See Eq. (2)), calculated with A and E values obtained by the Arrhenius plots in Fig. 6(b) and (d), respectively. The values of squares of residual sum, $\mathrm{R}^{2}$, in linear regression for obtaining the kinetic parameters are also given in Table 3, and they are not less than 0.94 for the main stages, indicating that the present pyrolysis behaviors are well described with two or three stages, first order pyrolysis scheme. 
Table 3. Kinetic Parameters for the Pyrolysis of CSC-coal Blends

\begin{tabular}{cccccc}
\hline CSC wt.\% Temp. $\left({ }^{\circ} \mathbf{C}\right)$ & $\mathbf{E}(\mathbf{k J} / \mathbf{m o l})$ & $\mathbf{A}\left(\mathbf{m i n}^{-1}\right)$ & $\mathbf{x}$ & $\mathbf{R}^{2}$ \\
\hline 1st stage & & & & & \\
\hline 100 & $152-334$ & 50.862 & 3,394 & $0.0-0.51$ & 0.9950 \\
80 & $152-334$ & 48.923 & 1,941 & $0.0-0.47$ & 0.9923 \\
60 & $152-334$ & 45.539 & 750 & $0.0-0.41$ & 0.9934 \\
40 & $152-334$ & 41.4 & 205 & $0.0-0.31$ & 0.9960 \\
20 & $152-334$ & 37.364 & 50 & $0.0-0.21$ & 0.9995 \\
(coal) 0 & $152-385$ & 17.5 & 0.13 & $0.0-0.12$ & 0.9900 \\
\hline 2nd stage & & & & & \\
\hline 100 & $335-472$ & 13.138 & 0.42 & $0.51-0.84$ & 0.9737 \\
80 & $335-473$ & 14.27 & 0.50 & $0.48-0.87$ & 0.9854 \\
60 & $335-472$ & 15.99 & 0.64 & $0.42-0.84$ & 0.9803 \\
40 & $335-473$ & 20.209 & 1.30 & $0.32-0.79$ & 0.9765 \\
20 & $335-472$ & 27.521 & 4.56 & $0.22-0.73$ & 0.9734 \\
(coal) 0 & $386-505$ & 64.112 & 2637 & $0.13-0.58$ & 0.9933 \\
\hline 3rd stage & & & & & \\
\hline 100 & $473-1,000$ & 0.3 & 0.0012 & $0.85-1.0$ & \\
80 & $474-1,000$ & 0.341 & 0.0013 & $0.88-1.0$ & \\
60 & $473-1,000$ & 2.845 & 0.0149 & $0.85-1.0$ & \\
40 & $474-1,000$ & 5.939 & 0.0425 & $0.80-1.0$ & 0.9543 \\
20 & $473-1,000$ & 8.773 & 0.0827 & $0.74-1.0$ & 0.9742 \\
(coal) 0 & $506-1,000$ & 13.293 & 0.1837 & $0.59-1.0$ & 0.9937 \\
\hline & & & & & \\
\hline
\end{tabular}
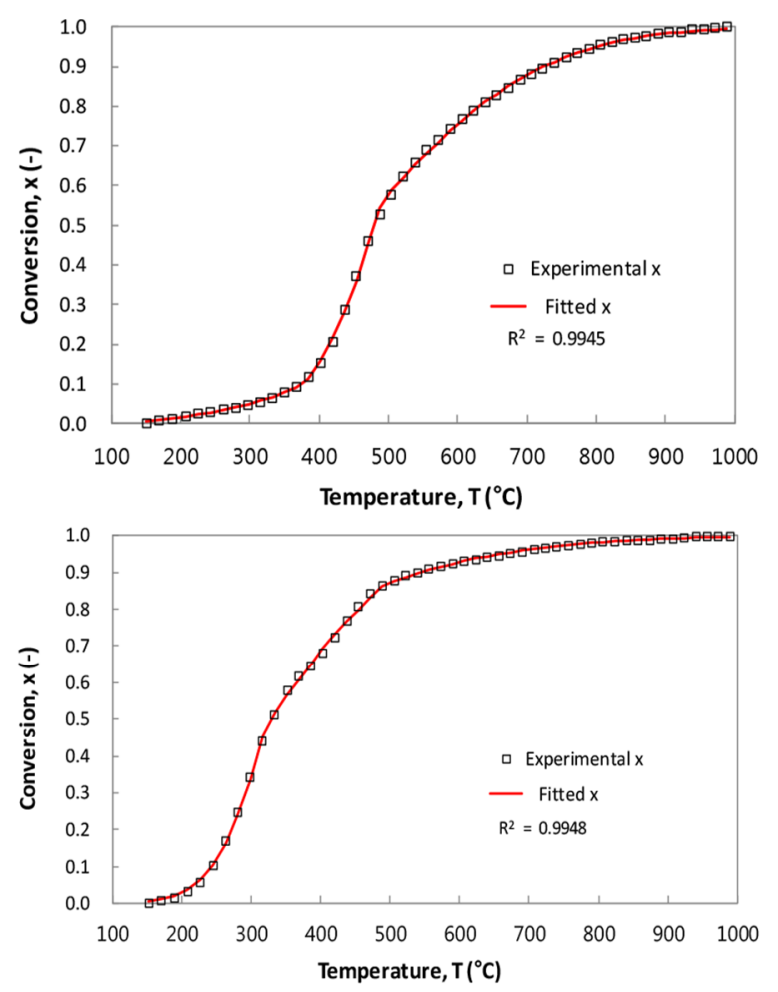

The pyrolysis behavior of coal is divided into three stages, as seen in Fig. 6(a) and (b). The initial stage ranges from $125^{\circ} \mathrm{C}$ to $385^{\circ} \mathrm{C}$ up to the conversion of $12 \%$, and the second stage take places in the range of $386-505^{\circ} \mathrm{C}$ corresponding to the conversion from $13 \%$ to $58 \%$. Finally, the relatively slow evolution of the remnant volatiles of $42 \%$ occurs at the temperature ranges of $506-1,000^{\circ} \mathrm{C}$. The kinetic parameters of coal for three stages are given in Table 3, and the values of $64 \mathrm{~kJ} / \mathrm{mol}$ and 2,637 $\mathrm{min}^{-1}$ for $\mathrm{A}$ and $\mathrm{E}$ in the main (second) stage are compatible with the values in the literature [15].

In the case of CSC, volatiles are evolved with three stages; the first stage gives the conversion of $51 \%$ up to the temperature of $334^{\circ} \mathrm{C}$, and the second one up to $472^{\circ} \mathrm{C}$ yields $84 \%$ conversion, and then the subsequent evolution of about $16 \%$ volatiles take places in the third stage. The kinetic parameters and the three stages of CR pyrolysis have not been reported in the literatures. The respective values of $\mathrm{A}$ for the first and second stages are $50.8 \mathrm{~kJ} / \mathrm{mol}$ and $13.1 \mathrm{~kJ} / \mathrm{mol}$ and these are respectively higher and lower values, compared to those of coal at each stage.

CSC-coal blends give three stages in their Arrhenius plots as seen Fig. 7(a) to (d) for the ratios of 20:80, 40:60, 60:40, and 80:20 for CSC and coal blends, respectively. As seen in Fig. 6, three stages are applied to both coal and CSC pyrolysis, so it is obvious that their blends are described with three stages pyrolysis. The decrease of CSC in the blends causes the decrease of E and A values in the first stage, and the increases in the second and third stages. When the fitted conversion data obtained with A and $\mathrm{E}$ values are compared to the experimental data, the values
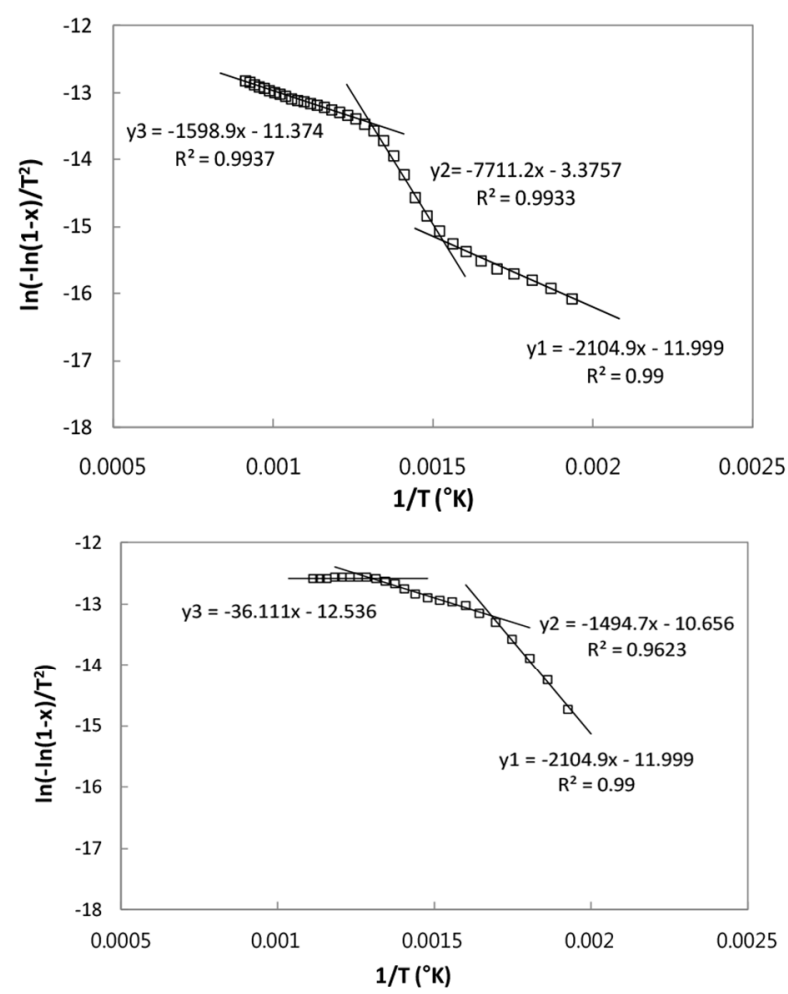

Fig. 6. Conversions and Arrhenius plots for the pyrolysis of coal and CSC. 

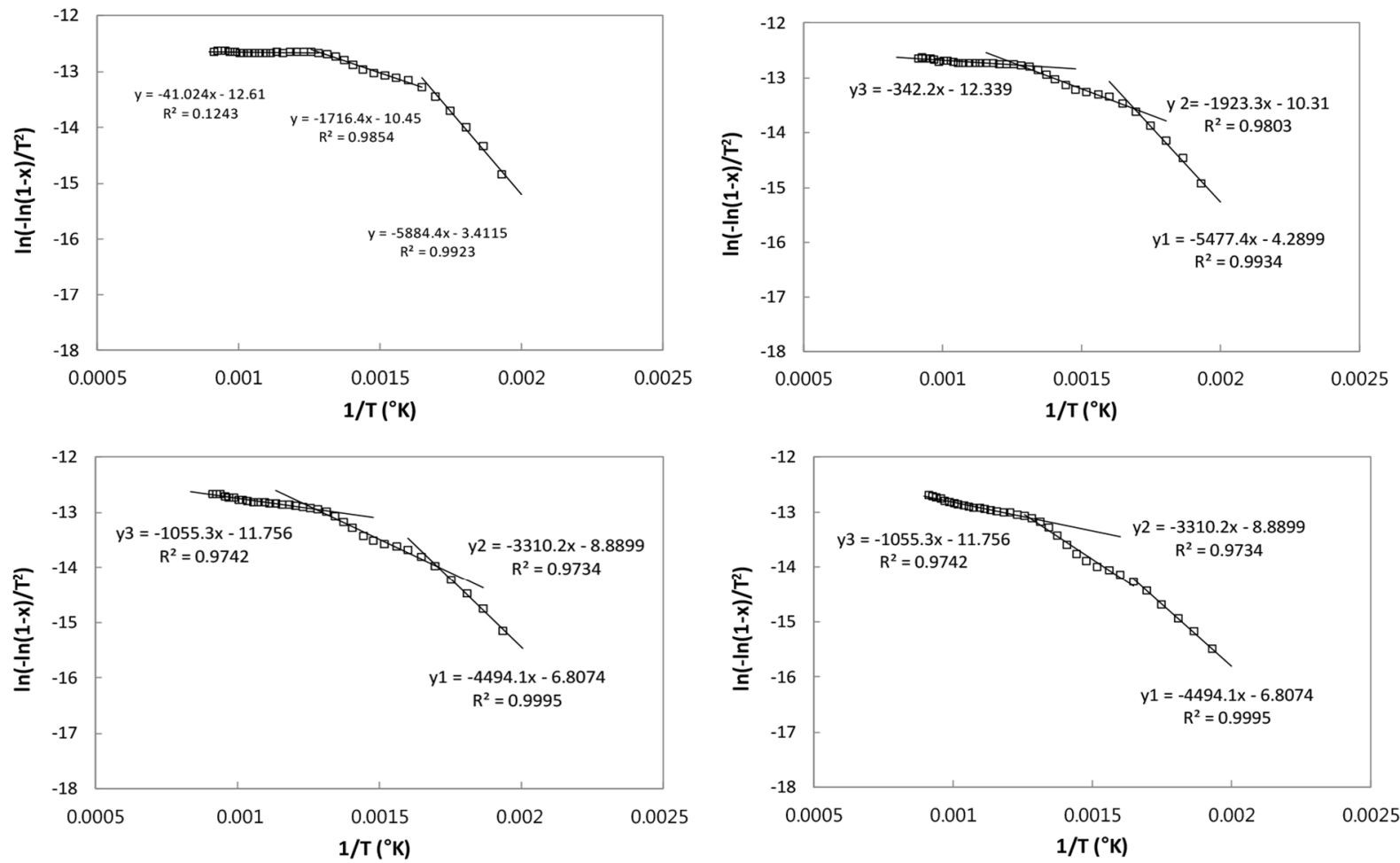

Fig. 7. Arrhenius plots for the pyrolysis of CSC-coal blends.
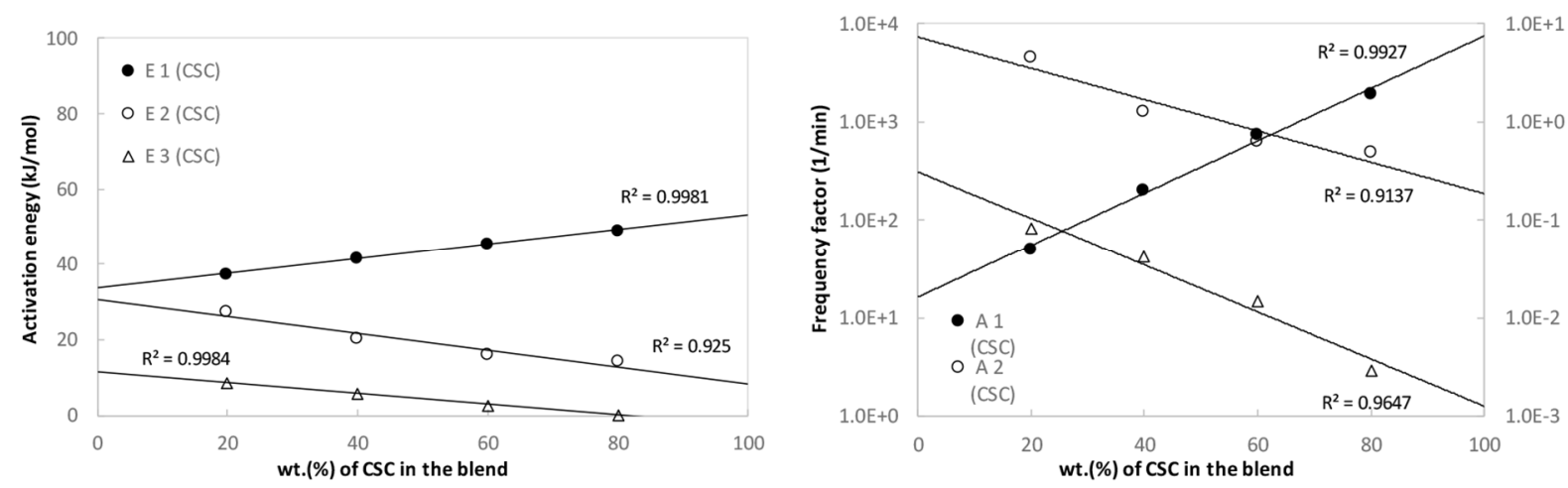

Fig. 8. Activation energy \& frequency factor for CSC-coal blends.

of $R_{2}$ are above 0.94 for the main stages, indicating that three stages are adequate for describing the pyrolysis of the present CSC-coal blends.

Fig. 8(a) shows the variation of activation energy depending on the blending ratios for CSC-coal blends, respectively. Since the lignocellulosic biomass promotes the pyrolysis of coal in the blend in the first stage where the temperature is relatively low, the activation energy, E1, linearly increases with the increase of lignocellulosic biomass in the blend. The second and third activation energy, E2 and E3, mainly stemmed from the coal in the relatively high temperature ranges, linearly decreases with the increase of coal in the blend. Fig. 8(b) shows the variation of frequency factors depending on the blending ratio for CSC-coal blends. The frequency factors for the present blends show the

same trends as observed in the activation energy distribution. The present linearity of activation energy and frequency factor against the blending ratio suggest the lack of interaction in the blend.

\section{Conclusions}

In this study, the non-isothermal pyrolysis characteristics of CSC-coal blends have been examined through TGA. For the CSC-coal blends, the first peaks in the DTG curves stem from lignocellulosic biomass and their shapes and heights are linearly proportional to the blending ratio. The calculated TG and DTG curves of the blends are almost overlapped with the experimental 
ones. The deviations between the experimental and calculated TG and DTG curves presented appreciably low values for the present blends. The char yields of the blends decrease with increasing CSC content in the blend, and there is a linear relationship between the char yield and blending ratio. The TGA results show that the additive rule is quite acceptable for describing the pyrolysis of the present blends and no-interaction between CSC and coal in the blends is presented.

The kinetic parameters for the pyrolysis of the present CSC-coal blends were obtained with the multi-stage, Coats and Redfern method. An increase of lignocellulosic biomass in the blend leads to a decrease in the activation energy and frequency factor in the first stage, and it causes an increase in the second and third stages. The kinetic parameters for the CSC-coal blends are linearly varied with blending ratio.

\section{Acknowledgments}

This work was supported by KOWEPO (Korea Western Power Co.), EWPC (Korea East-West Power Co.), and Korea Electric Power Corporation (KEPCO) funded by project No. R15GF04.

\section{References}

1. Loow YL, Wu TY, Tan KA, et al. Recent advances in the application of inorganic salt pretreatment for transforming lignocellulosic biomass into reducing sugars. J. Agr. Food Chem. 2015;63;8349-8363.

2. Loow YL, Wu TY, Jahim JM, Mohammad AW, Teoh WH. Typical conversion of lignocellulosic biomass into reducing sugars using dilute acid hydrolysis and alkaline pretreatment. Cellulose 2016;23;1491-1520.

3. Loow YL, Wu TY, Lim YS, et al. Improvement of xylose recovery from the stalks of oil palm fronds using inorganic salt and oxidative agent. Energ. Convers. Manage. 2017;138;248-260.
4. Fernando R. Fuels for biomass cofiring. IEA Clean Coal Centre, CCC/102; 2005.

5. Fernando R. Cofiring high ratios of biomass with coal. IEA Clean Coal Centre, CCC/194; 2012.

6. Gangil S. Dominant thermogravimetric signatures of lignin in cashew shell as compared to cashew shell cake. Bioresour. Technol. 2014;155:15-20.

7. Das P, Ganesh A. Bio-oil from pyrolysis of cashew nut shell-a near fuel. Biomass Bioenerg. 2003;25:113-117.

8. Tsamba AJ, Yang W, Blasiak W. Pyrolysis characteristics and global kinetics of coconut and cashew nut shells. Fuel Process. Technol. 2006;87:523-530.

9. Tsamba AJ, Yang W, Blasiak W, Wójtowica MA. Cashew nut shells pyrolysis: Individual gas evolution rates and yields. Energy Fuels 2007;21:2357-2262.

10. Yuliana M, Huynha L, Hob QP, Truongb C, Ju Y. Defatted cashew nut shell starch as renewable polymeric material: Isolation and characterization. Carbohyd. Polym. 2012;87: 2576-2581.

11. Daniel N, Henrik T, Arlindo M, Luís T, Alberto GB. Characterization and prediction of biomass pyrolysis products. Prog. Energ. Combust. Sci. 2011;37;611-630.

12. Meng H, Wang S, Chen L, Wu Z, Zhao J. Thermal behavior and the evolution of char structure during co-pyrolysis of platanus wood blends with different rank coals from northern China. Fuel 2015;158:602-611.

13. Wu Z, Wang S, Zhao J, Chen L, Meng H. Synergistic effect on the thermal behavior during co-pyrolysis of lignocellulosic model components blend with bituminous coal. Bioresour. Technol. 2014:169:220-228.

14. Lu KM, Lee WJ, Chen WH, Lin TC. Thermogravimetric analysis and kinetics of co-pyrolysis of raw/torrefied wood and coal blends. Appl. Energ. 2013;105:57-65.

15. Anca-Couce A, Berger A, Zobel N. How to determine consistent biomass pyrolysis kinetics in a parallel reaction scheme. Fuel 2014;123:230-240. 